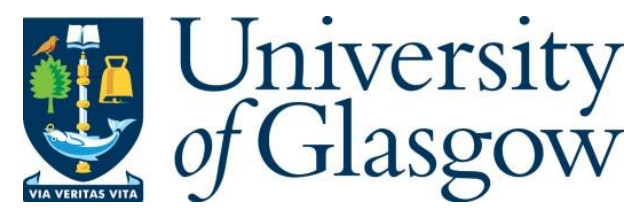

Khosravi, S. and Ghannam, R. (2021) Calling all engineers: we need you! IEEE Potentials, 40(5), pp. 14-17.

There may be differences between this version and the published version. You are advised to consult the publisher's version if you wish to cite from it.

$\underline{\text { http://eprints.gla.ac.uk/235063/ }}$

Deposited on: 25 February 2021

Enlighten - Research publications by members of the University of Glasgow http://eprints.gla.ac.uk 


\title{
Calling All Engineers: We Need You!
}

\author{
Sara Khosravi, Student Member, IEEE, and Rami Ghannam*, Senior Member, IEEE
}

\begin{abstract}
Engineering is one of the oldest professions, along with divinity, medicine and law. Without engineering, the world around us would simply not exist. Now, more than ever, engineering graduates are needed to drive national economic growth and development. However, there is a sustained shortage of engineers, since fewer students are enrolling in engineering degrees each year. We therefore highlight the importance of engineers in society and the challenges in teaching engineering curricula to undergraduate students. Clearly, a paradigm shift in the way engineering is taught at universities is necessary to ensure that bright minds, especially young females, are attracted to this profession. Otherwise, gender parity will only be achieved by 2050! We discuss how technology integration and the use of active learning methods can be adopted in teaching curricula to help retain and engage students. Towards the end of our article, we also provide recommendations for how some of these challenges can be remedied.
\end{abstract}

Index Terms - Engineering Education, Pedagogy, Technology Enhanced Learning

I F you're reading this, it's probably too late! You've probably decided to take the deep dive into the crazy world of engineering and you're now having second thoughts. Rest assured, engineering is a rewarding career and people with engineering degrees have a broad range of career options. However, not all of us are completely satisfied with the way we were taught at university. We therefore aim to highlight some of the issues with engineering education, so that you can be the catalyst for change in the near future.

Engineering has given us the world we live in. It is an incredibly diverse activity covering many areas, which is perhaps why it has held a variety of meanings at different times and places. Essentially, the word 'engineer' stems from the Latin word 'ingenium', which means ingenuity or cleverness and invention. In fact, engineers are trained to use both scientific knowledge and mathematics on the one hand to create technologies and infrastructures to address human, social and economic challenges. They must also connect societal needs with innovation and commercial applications. Consequently, engineering lies in our everyday lives and the relationship between science, technology and engineering can be described as shown in figure 1 .

Not many people know what engineers do, which is perhaps why almost half of 11 to 19 year olds know nothing about the profession. Despite their importance in society, fewer students are enrolling in engineering degrees. For example, around $8 \%$ of the UK's graduates are awarded an engineering degree, in comparison to around $19 \%$ choosing a degree in art, or

S. Khosravi and R. Ghannam are with the Engineering Education Research Group, James Watt School of Engineering, University of Glasgow, G12 8QQ Glasgow, UK (e-mail:s.khosravi.1@ research.gla.ac.uk and rami.ghannam@glasgow.ac.uk).

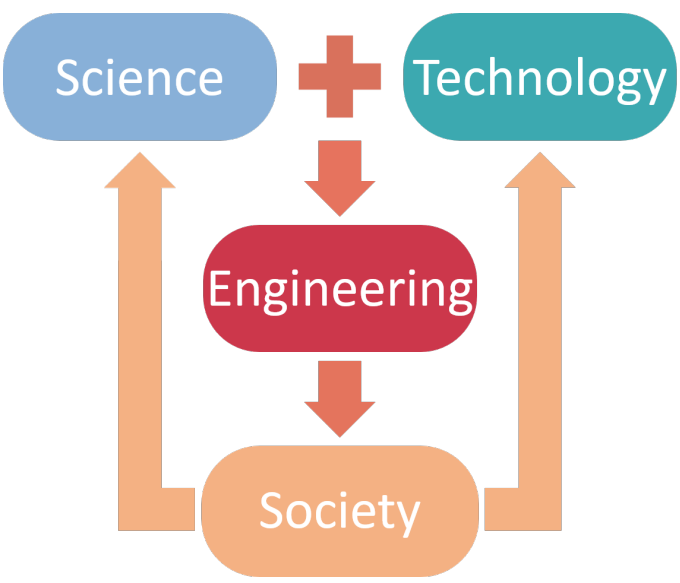

Fig. 1: Relationship between engineering, science and technology. Engineers develop the products and services that societies need.

$19 \%$ in business, or $17 \%$ in natural sciences. It is therefore no surprise that the UK currently ranks 14th in the Royal Academy of Engineering's 'Engineering Index', as it needs to double the current number of graduates annually to maintain its competitiveness in the global economy. These graduates are essential for addressing critical issues such as energy security, clean water, climate change and health. One way to fill this shortage is to tackle the huge gender disparity and to encourage more females to apply.

But why is this the case? Why are more students dropping out? Why are few female students enrolling in engineering degrees? According to professionals and academics, one of the main reasons is the way engineering is taught at universities. In other words, 'engineering education' is the culprit!.

Looking back into how engineering was taught, universities only began teaching it in the 17th century, particularly in technical universities located in Germany and the Czech Republic. Despite Britain triggering the industrial revolution in the early 18th Century, it was a century later that engineering education emerged in British universities. Moreover, events such as the two world wars during the 20th Century further accelerated the advancement of engineering education around the world. Figure 2 summarizes the history of engineering education and the events that had a significant impact on it. Despite the emergence of new specialisations and the continuously evolving course content, teaching methods adopted by these institutions have largely stayed the same.

A compelling body of research now seems to suggest that there are five main problems or challenges in engineering education, which we summarise in figure 3 . These challenges are:

1) Enrolment and retention. As previously mentioned, 


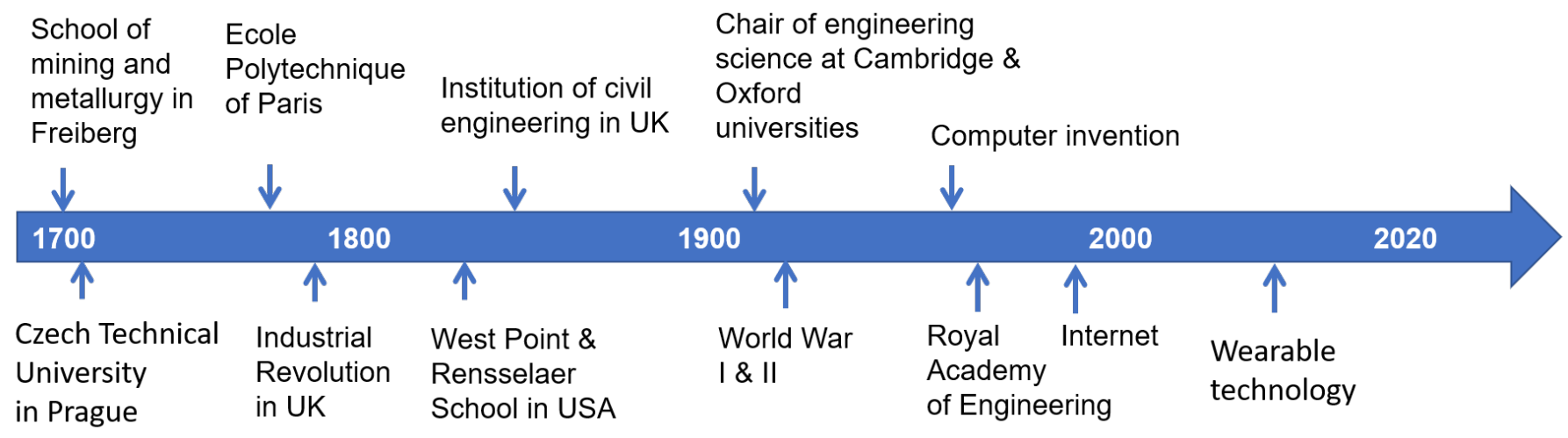

Fig. 2: Main historical events leading to development of engineering education.

there is sustained shortage of engineering students due to low enrollment numbers, especially in Western countries.

2) Employer's attributes. Existing teaching approaches are disconnected from market needs and do not produce the innovators required by industry.

3) Collaborative learning. There is a lack of shared learning opportunities between governments, industry and academia.

4) Diversity. Engineering is still a predominantly male discipline, where females are often outnumbered six to one. Moreover, it is sometimes considered 'difficult, complicated and dirty', as well as being a 'man's profession'.

5) New and emerging technologies. Continuous developments in digital and semiconductor technology have made it challenging to cover an entire engineering discipline within a typical four year undergraduate programme. Moreover, faculty members are not effectively embedding these technologies in their engineering pedagogy.

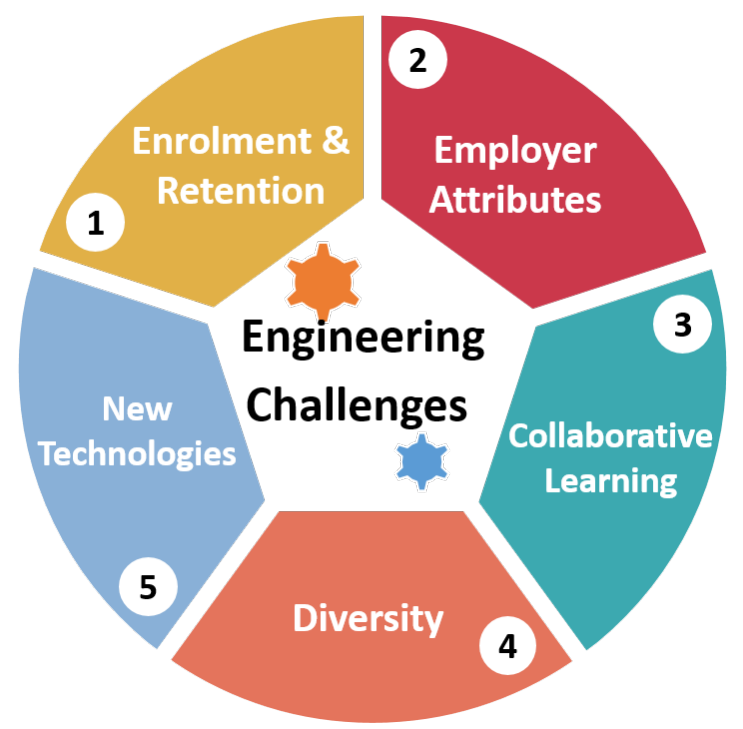

Fig. 3: The five main challenges in the current engineering education
Starting with the first challenge, there is clearly a lack of interest in younger people choosing engineering as their field of study.

In fact, the main reason for low enrolment and retention rates was the traditional teaching approach adopted by professors. Accordingly, curricula need to be more innovative and correlated with young generation interests. However, this can only be accelerated if institutions reward professors for their teaching excellence, in addition to their research productivity. Otherwise, they will be reluctant to make the necessary changes.

Furthermore, from the employers' perspective, graduates often leave university without the "soft" skills needed by the continuously shifting job market. Skills such as teamwork, collaboration, communication, the ability to analyse and solve problems, as well as the ability to develop new or innovative ideas, directions, opportunities or improvements. Therefore, these missing connections between engineering graduate attributes and employers' expectations have to be well defined in close collaboration with industry and policymakers. In this way, the third challenge of collaborative and interest-led learning can also be addressed.

Diversity is another issue that has received plenty of criticism. According to data reported by the UK's Higher Education Statistics Agency (HESA), only 20.7\% of engineering and technology students in higher education are female. In fact, the number of female students has increased from $16.3 \%$ in $2009 / 10$ to $20.7 \%$ in $2018 / 19$. However, considering this modest growth rate (Fig 4), we predict achieving gender parity by 2050 ! Compared with the balance and diversity in other disciplines, a paradigm shift in engineering education is therefore essential to attract more bright minds to this profession. Nontraditional teaching methods are therefore needed. For example, active learning techniques such as Team Based Learning (TBL) and Project Based Learning (PBL) techniques can be introduced in engineering curricula so that students can re-use their skills across a range of different modules. These teaching approaches have demonstrated a positive impact on student satisfaction and performance. They are also ideally suited to the engineering profession, which relies on tackling problems in teams or groups. Besides, since when do engineers work in isolation? 


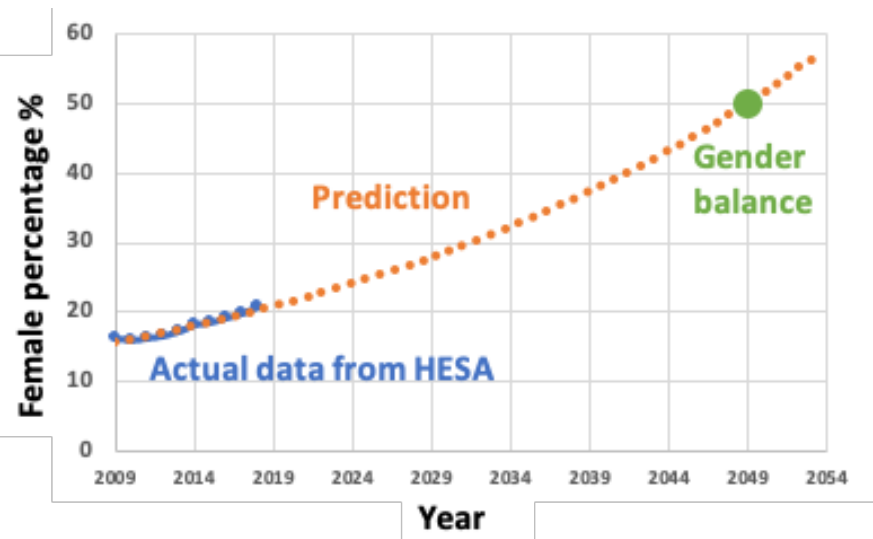

Fig. 4: Diversity and gender balance prediction in the UK's engineering students. The blue line shows actual data from the UK's Higher Education Statistics Agency, while the dashed orange line denotes our prediction. The green dot shows the expected gender balance by 2050 .

Moreover, state of the art digital technologies can be seamlessly integrated in curricula to help students achieve their learning goals. In particular, they can help shift student learning away from traditional teacher-centric education. Such emerging technologies include, but are not limited to, social media platforms, virtual and augmented reality devices, mobile learning devices, computers, and collaborative learning technologies. These tools can provide students with an effective opportunity to develop a stronger understanding of their curriculum, especially if they are carefully matched to the intended learning outcomes. Certainly, innovations in information and communications technology (ICT) are on the verge of transforming traditional-based teaching to digitalbased learning. Perhaps mobile and wearable devices will enable a new generation students to be attracted into engineering studies. However, further studies and investigations are necessary to fully appreciate the limitations, obstacles and affordances of these devices in engineering education.

No doubt, engineering is an important profession that has an immense impact on global economies. However, there has been a sustained shortage of high quality engineering graduates, especially in Western countries. Moreover, gender disparity is a striking issue and females only account for around $20 \%$ of engineering graduates, whereas they account for more than half the total student population. Therefore, all the evidence seems to suggest that we can overcome these challenges by moving away from traditional teaching methods that rely on the 'banking' approach. The integration of technology, or technology enhanced education, as well as the use of active learning techniques are expected to remedy these issues. Some of these techniques include Team Based Learning, which is a collaborative student centred teaching method. Otherwise, we will continue to see dwindling student numbers and gender parity that's likely to take place in three decades.

\section{REFERENCES}

[1] Organisation for Economic Co-operation and Development, "Distribu- tion of graduates and entrants by Field," https://stats.oecd.org/Index. aspx? DataSetCode=EAG_GRAD_ENTR_FIELD $\backslash \#, \quad 2020$, accessed: 2020-11-08.

[2] Royal Academy of Engineering, "New global study proves link between engineering and economic development," https://www.raeng.org.uk/news/news-releases/2016/september/ new-global-study-proves-link-between-engineering-a, 2016, accessed: 2020-11-09.

[3] H. Perkin, "History of universities," in International handbook of higher education. Springer, 2007, pp. 159-205.

[4] J. Maier, "Engineering skills for the future: The 2013 perkins review revisited," 2019.

[5] EngineeringUK, "Engineering UK report," https://www.engineeringuk. $\mathrm{com} /$ media/232300/engineering-uk-report-2020-executive-summary. pdf, 2020, accessed: 2020-11-09.

[6] K. Wall, Engineering: issues, challenges and opportunities for development. UNESCO, 2010.

[7] A. R. Carberry and D. R. Baker, "The impact of culture on engineering and engineering education," in Cognition, metacognition, and culture in STEM education. Springer, 2018, pp. 217-239.

[8] C. S. Nair, A. Patil, and P. Mertova, "Re-engineering graduate skills-a case study," European journal of engineering education, vol. 34, no. 2, pp. 131-139, 2009.

[9] HESA, "Open Data and Official Statistics," https://www.hesa.ac.uk/ data-and-analysis, 2020, accessed: 2020-11-11.

[10] R. Ghannam and W. Ahmad, "Teaching teamwork to transnational students in engineering and technology," Compass: Journal of Learning and Teaching, vol. 13, no. 2, pp. 1-17, 2020.

[11] R. Ghannam, "Do you call that a lab notebook?" IEEE Potentials, vol. 39, no. 5, pp. 21-24, 2020.

\section{AUTHORS}

Sara Khosravi received her B.S. degree in Management in 2013, and the M.S. degree in International Business and Economics from University of Pavia, Italy, in 2016. Her M.S. dissertation was concerned with the impact of renewable energy on electricity, heat and transportation in the UK. She is currently pursuing the Ph.D. degree in Engineering Education at the University of Glasgow, UK. Her research interests are in engineering education, which includes investigating innovative learning and teaching methods using wearable devices.

Rami Ghannam is a lecturer (Assistant Professor) in Electronic and Nanoscale Engineering at the University of Glasgow. He obtained his BEng degree in Electronic Engineering from King's College and was awarded the Siemens Prize. He subsequently received his DIC and MSc degrees from Imperial College London, as well as his $\mathrm{PhD}$ from the University of Cambridge in 2007. He held previous industrial positions at Nortel Networks and IBM Research GmbH. His research interests are in Energy Harvesters and Engineering Education. He is a Senior Member of the IEEE, a Senior Fellow of Glasgow's RET scheme and serves as Scotland's Regional Chair of the IEEE Education Society. 